\title{
Mapping Hazard Zones, Rapid Warning Communication and Understanding Communities: Primary Ways to Mitigate Pyroclastic Flow Hazard
}

\author{
Franck Lavigne, Julie Morin, Estuning Tyas Wulan Mei, \\ Eliza S. Calder, Muhi Usamah and Ute Nugroho
}

\begin{abstract}
Protection against the consequences of Pyroclastic Density Currents (PDCs) is almost impossible due to their high velocity, temperature, sediment load and mobility. PDCs therefore present a challenge for volcanic crisis management in that specific precautionary actions, essentially evacuations, are required to reduce loss of life. In terms of crisis communication for PDC hazards, there are three challenging questions that arise in terms of reducing risk to life, infrastructure and livelihoods. (1) How do we accurately communicate the hazardous zones related to potential PDC inundation? The areas exposed to PDC hazard are difficult to assess and to map. In terms of risk/crisis management, the areas considered at risk are usually those that were affected by PDCs during previous eruptive episodes (decades or centuries ago). In case of "larger-than-normal" eruptions, the underestimation of the hazard zone may lead to refusals to evacuate in the "newly" threatened area. Another difficulty in assessing the PDC hazard zones relate to their transport processes that allow surmounting of the topography and in some cases across the surface of water. Therefore warning systems must be able to cover vast areas in a minimum of time. (2) How do we efficiently warn people in time? PDCs are extremely mobile and fast. It is therefore necessary to raise the alert early enough before the onset of the first PDCs. A challenging question in terms of crisis communication is related to the
\end{abstract}

F. Lavigne $(\bowtie)$

Laboratoire de Géographie Physique,

Université Paris 1 Panthéon-Sorbonne, Meudon,

France

e-mail: franck.lavigne@univ-paris1.fr

J. Morin

Laboratoire Magmas et Volcans,

Université Clermont Auvergne, CNRS, IRD, OPGC,

Clermont-Ferrand F-63000, France

E.T.W. Mei

Fakultas Geografi, Universitas Gadjah Mada,

Yogyakarta, Indonesia

Advs in Volcanology (2018) 107-119

https://doi.org/10.1007/11157_2016_34

(C) The Author(s) 2017

Published Online: 26 May 2017

\section{E.S. Calder}

School of GeoSciences, University of Edinburgh, James Hutton Rd, The Kings Buildings, Edinburgh, UK

M. Usamah

PYDLOS, Universidad de Cuenca, Cuenca, Ecuador

U. Nugroho

Universitas Padjadjaran, Bandung, Indonesia 
type of tools used by the local authorities, modern and traditional tools both of which have advantages and disadvantages. (3) Why are people reluctant to evacuate? Local inhabitants can be reluctant to evacuate during a crisis if traditional warning signs or signals they are familiar with are lacking, if they don't receive both traditional and official warning, and because they may lose their livelihoods. Thus a deeper understanding of the at-risk communities and efficient dissemination of information are key issues in order to reduce vulnerability in PDC hazard regions.

\section{Keywords}

Pyroclastic density currents - Risk communication - Crisis management • Warning $\cdot$ Evacuation $\cdot$ Risk perception

\section{Introduction}

Pyroclastic Density Currents (PDCs) are rapid flowage phenomena that involve various proportions of volcanic gas and fragmented volcanic rock at high temperatures. PDCs encompass dense pyroclastic flows, which tend to be more topographically controlled, and dilute pyroclastic surges that are less topographically controlled and can surmount topographic obstacles, or travel across the surface of bodies of water. Both dense flows and dilute surges destroy almost everything in their path and therefore protection against the consequences of PDC inundation is almost impossible. In some countries, anti-PDC bunkers have been built in high hazard prone areas to provide a safe shelter to a limited number of people in the situation that they are unable to evacuate on time. It was demonstrated in 2006 on Merapi (Indonesia) that they are not always effective, as two people died trapped in the bunkers where they took refuge (Gertisser et al. 2011). Moreover, hard engineering structures such as SABO dams may actually accentuate the avulsion process of PDCs, e.g. in 2006 and 2010 at Merapi (Lube et al. 2011), or Tungurahua in 2006 (Stone et al. 2014). Thus, PDCs present a challenge for volcanic crisis management in that specific precautionary actions are required to reduce loss of life.
The improvement of crisis management capabilities is based, on one hand, on PDC monitoring and early warning systems as well as robust communications that are not likely to be compromised for example by power failure and, on the other hand, on preparedness of stakeholders and population (MIAVITA Team 2012).

This chapter discusses three challenging questions in reducing the risk associated with PDCs: (1) How should we accurately communicate the hazardous zone related to potential PDC inundation? (2) How should we efficiently warn people in time? (3) Why are people oftentimes reluctant to evacuate and how should we improve the propensity for people to accept and undertake evacuations?

These points are addressed through examples, mostly focusing on Merapi, and other Indonesian volcanoes as well as other volcanoes around the world. This chapter concludes with a discussion on ways to improve volcanic risk management in areas prone to PDC hazards.

\section{How Can We Communicate PDC Hazard Zones?}

The areas exposed to PDC hazard are difficult to accurately assess and to map. In terms of risk/crisis management, the areas considered at 
risk are usually those that were affected by PDCs during the last decades or centuries. Scientists in charge of volcano monitoring often use a "reference eruption", the extent of volcanic deposits of which are used to gauge inundation extent for future eruption scenarios in operational hazard maps. For instance, the "danger zones" maps used in Indonesia for emergency planning are provided by the Center of Volcanology and Geological Hazards Mitigation (CVGHM). These maps typically display two zones threatened by PDC hazard: the KRB III (KRB stands for Kawasan Rawan Bencana in Indonesian or Hazard Prone Area in English) encompasses areas located close to the summit, frequently affected by dome-collapsed pyroclastic flows, lava flows, rock falls and ejected rock fragments. The KRB II is affected by less frequent and longer runout pyroclastic flows, lahars, volcanic ash fall, and ejected rocks. At Merapi for example, the boundaries of hazard zone III and II were based, until 2010, on the distribution of volcanic products of the largest eruptions of the 20th century. Therefore the maximum distance of the KRB II did not exceed $15 \mathrm{~km}$, which was the approximate maximum extension of the 1930 ,
1961, and 1969 PDCs. Since its first edition in 1978 (Pardyanto et al. 1978, Fig. 8.1), the volcanic hazards map has been widely disseminated among the communities at risk through the local authorities and non-governmental organizations (NGOs). Although this map was updated following the 2006 eruption (Mei and Lavigne 2012), the contingency plan created in 2009 still did not consider a plinian or subplinian eruption scenario such as the one that occurred in 1872 . Several areas affected by the subsequent and devastating 2010 PDCs, the length of which were substantially longer than expected $(17 \mathrm{~km}$ from the summit), had not been included in the danger zone. As a result 53 people who were resisting evacuation or who were late in the process of evacuating were killed in Bronggang, a village located $13.5 \mathrm{~km}$ to the south of Merapi, when dilute surges detached from their parent flows in the adjacent Gendol River and entered the village (Jenkins et al. 2013). Among the survivors, several inhabitants who were unprepared for evacuation took a wrong evacuation route too close to the river (Mei et al. 2013). Since the 2010 eruption, the hazard map has been revised (Fig. 8.1).
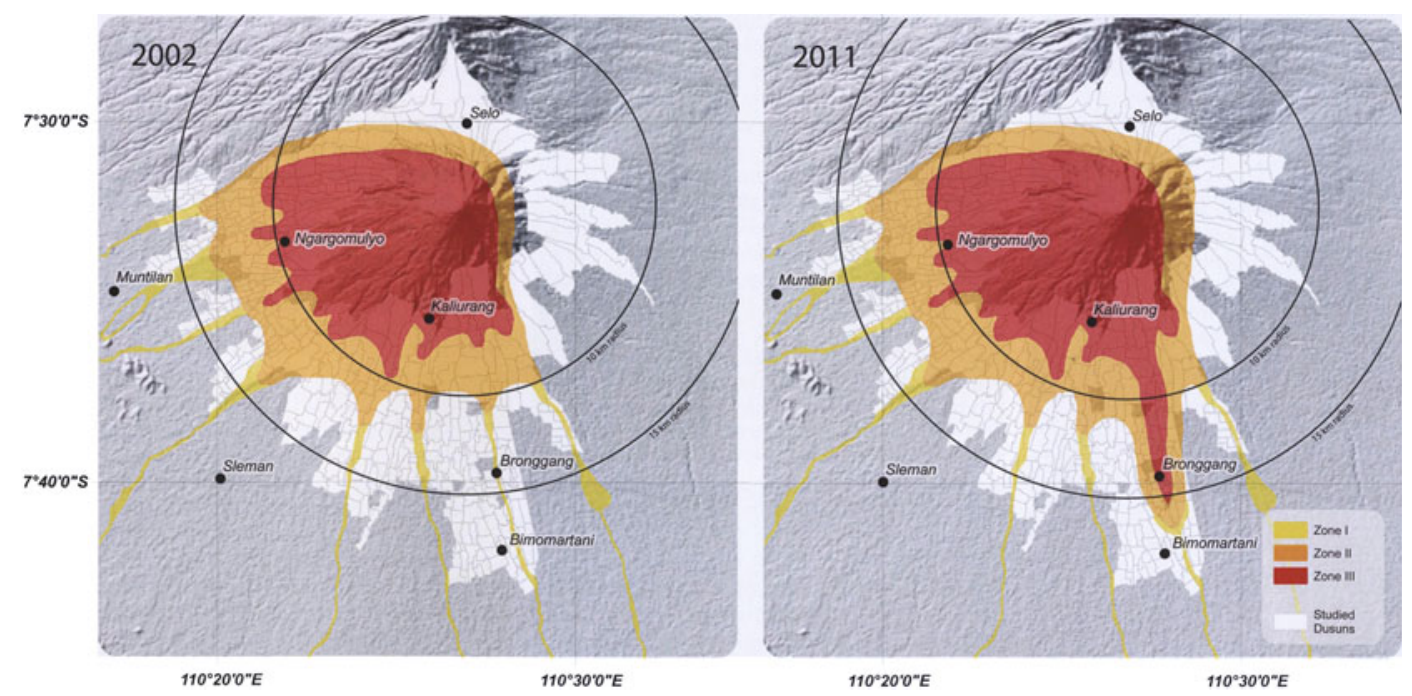

Fig. 8.1 The Merapi volcano hazard map designed by the Indonesian Center of Volcanology and Geological Hazard Mitigation (CVGHM) in 2002 (CVGHM 2002) and after its revision in 2011 (CVGHM 2011) 
Although the local authorities are often aware of the worst-case scenario provided by the volcanologists, they cannot use it for contingency planning, i.e. for risk management. Using the worst case scenario for a background hazard map is actually impractical since many existing communities are established on deposits from large eruptions, and an eruption is unlikely to reach worst case without some precursory activity. However, all possibilities should be discussed between volcanologists and authorities well before a crisis, so that outline contingency planning can be made if significant escalation does occur. Communities can live within hazard zones, if they are aware of the threat and there is good planning for evacuations in the event of an escalation. Maps are commonly adjusted as a crisis evolves, as shown in the cases of Merapi. During the 2012 Tongariro eruption crisis in New Zealand, Leonard et al. (2014) highlighted the importance and complementary roles of three map types for communicating volcanic hazard information: background hazard, crisis hazard and ashfall prediction maps. In developing hazard maps there are a range of key points to consider in terms of message, presentation and basis for each map type. For example, perspective view has been shown to increase map readability and public self-location accuracy (Haynes et al. 2007b; Nave et al. 2010). Following Leonard et al. (2014), PDC hazards need careful quantification through modelling. For rapid crisis PDC hazard map zone development the critical factors are (1) having access to and experience in running flow models, (2) having those models tested against the past and expected future parameters of a volcano and (3) having access to the computing resources needed to run enough scenarios in a short (day to days) timeframe.

The main difficulty in communicating PDC hazardous zones occurs when the hazard is almost unknown, or has been forgotten by local people over time after a few generations, such as on the slopes of the Mount Pelée on the island of Martinique before the 1902 eruption (Leone and
Lesales 2009). One day before the total destruction of Saint-Pierre by pyroclastic surges, a scientific expert from mainland France claimed that "Saint-Pierre is not more threatened by the Pelée volcano than Napoli by the Vesuvius volcano". This scientist was not aware that dilute pyroclastic surges could occur at Mount Pelée (such as during the plinian eruption in $1300 \mathrm{AD}$ ), since these phenomena were not yet known (Lacroix 1904). Examples as this one are numerous in volcanic areas. For instance, most of the villages of the northern and southeastern coast of Lombok Island (Indonesia) have been built on pumice PDC deposits emplaced during the 1257 AD ultraplinian eruption of the Samalas volcano (Lavigne et al. 2013).

\section{How Do We Warn People in Time?}

\subsection{Difficulties in Providing Timely Warnings}

PDCs are extremely mobile, generally travelling at tens to hundreds of $\mathrm{km} / \mathrm{h}$. Therefore alerts need to be provided at least several hours before the first PDC occurs. Unfortunately, local populations are not always warned by the authorities before an imminent eruption, for various reasons. In case of gravitational collapses of silicic lava domes, which trigger 'Merapi-type' pyroclastic flows, warning people is not possible until the occurrence of the collapse itself: reliable precursory signals have not yet been identified, as observed on Merapi on 22 November 1994 (Abdurachman et al. 2000), although in some cases, the characteristics of seismic activity can change leading up to a collapse e.g. at Soufriere Hills (Cole et al. 1998). In some cases, the absence of warning may be related to traditional scepticism in technological predictions, when local officials refuse to listen to the scientific forecasts and predictions at the very beginning of a volcanic crisis (IAVCEI Subcommittee for Crisis Protocols 1999). Additional external 
drivers may prevent an alert by the local authorities (the mayor in many cases), e.g. local elections, as observed at the beginning of the 1902 eruption of Mount Pelée in Martinique (Lacroix 1904).

\subsection{Modern Versus Traditional Warning Tools}

The type of tools used to communicate warnings by local authorities in times of crisis is critical to ensuring an effective messaging. Modern tools like sirens are increasingly used as "official" warning systems on active volcanoes. In developing countries, however, the areal distribution of sirens is not homogenous, e.g. around Merapi in Indonesia (Fig. 8.2). Based on a survey carried out among 1969 people in shelters during the 2010 eruption of Merapi, only $16 \%$ of the people were warned by sirens before the PDCs totally destroyed the slopes of the volcano (Fig. 8.3, Mei et al. 2013), whereas most people received evacuation alerts directly from the head of village (54\%), or from neighbors (11\%).

The warning signal may be also transmitted by a mobile system installed on the fire department's vehicles (e.g. in France). In Japan, the

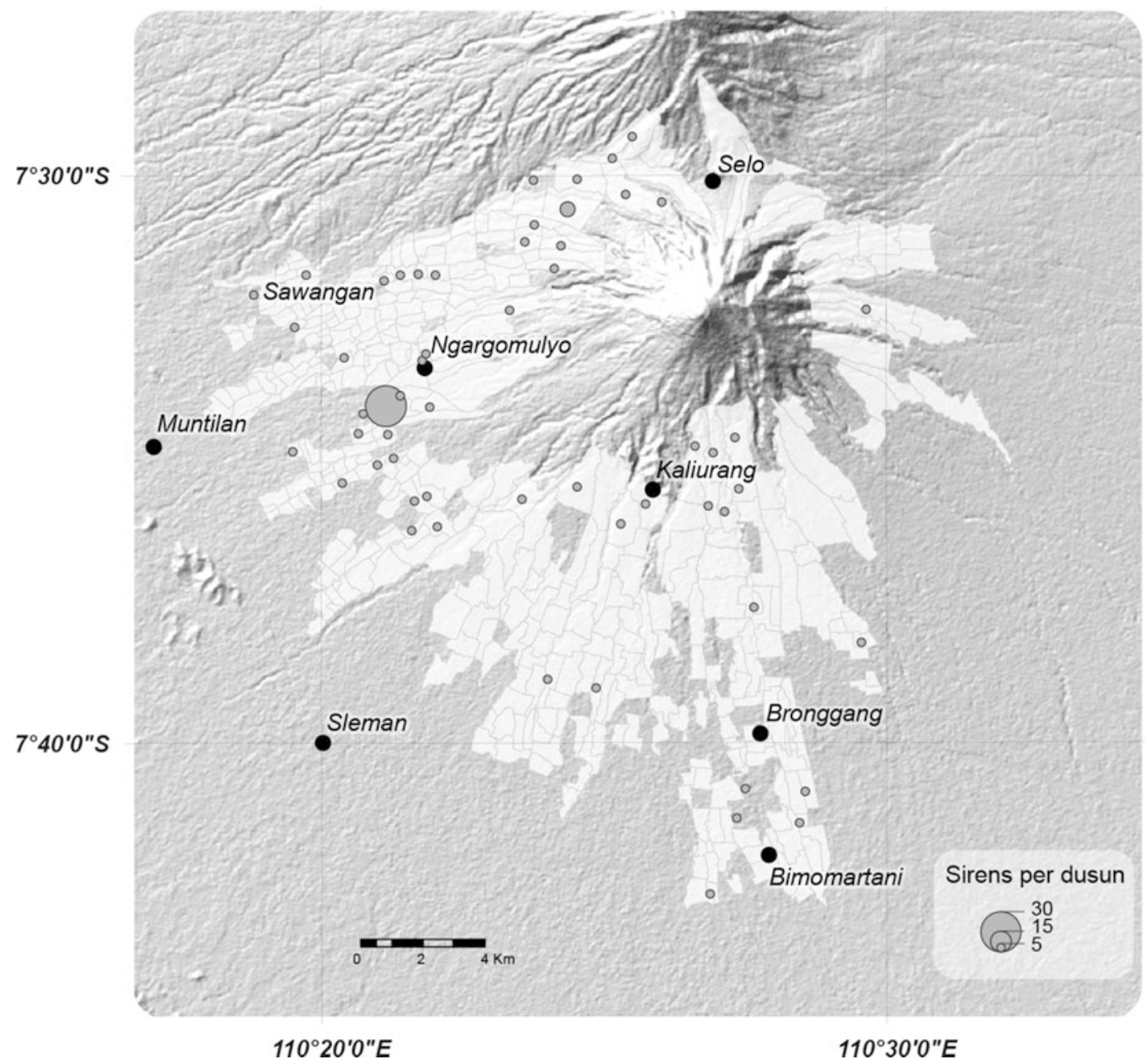

Fig. 8.2 Siren distribution around the flanks of Merapi, Indonesia. Source Lavigne et al. (2015), based on Mei et al. (2013) 
Fig. 8.3 The source of warnings during the 2010 volcanic crisis of Merapi, Indonesia (adapted from Mei and Lavigne 2013)

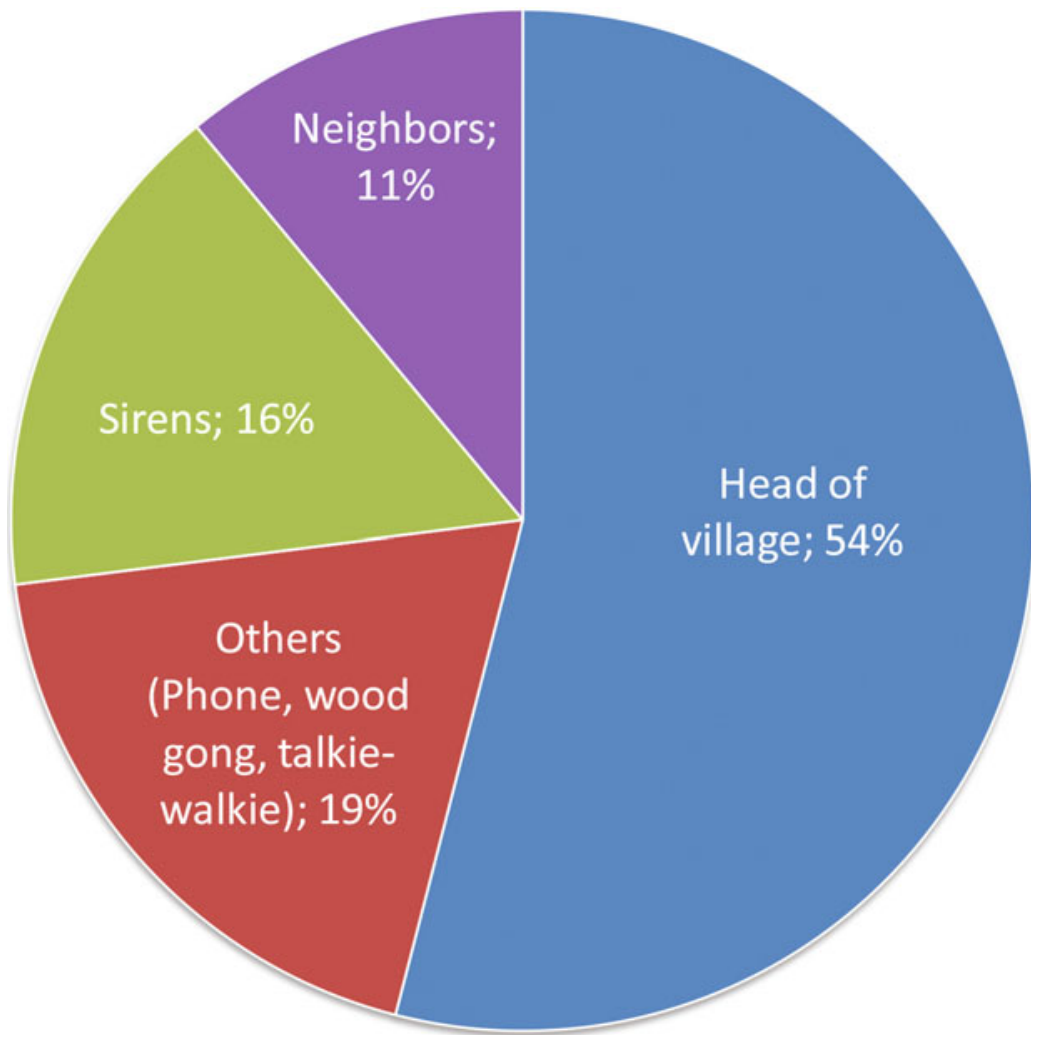

J-Alert system, launched in 2007, aims to allow government officials to address the population directly via loudspeakers, e.g. in case of an eruption alert.

Other modern tools are widely used to warn people of imminent PDCs. Should a volcanic event happen, local people considered at risk may receive a warning message in the form of SMS Text Message and/or Email onto their cell phones, smart phones or other electronic devices like iPads, Laptops, Desktop computers, etc. Usually, this type of warning message would be distributed by Civil Defense Corps and includes all the hazards that could trigger an emergency situation, not only volcanic hazards, e.g. the app provided in Auckland (www. aucklandcivildefence.org.nz/Alerting/Get-theApplications) or in Hawaii (http://www. hawaiicounty.gov/active-alerts). At Tongariro Volcano in New Zealand, for example, an alert is provided by the key scientific institution to related agencies (e.g. Civil Defense and Emergency Management) and the media through online bulletins as well as direct communication through its emergency network. This bulletin is also accessible by the public via their network website and social media (Leonard et al. 2014). In Japan, real-time volcanic warning is available to the public on the website (JMA 2015). Beyond volcanic hazards, Japanese agencies send out SMS alerts to all registered mobile phones in the country (Pearson 2015).

Although modern tools are growing, traditional tools are still considered as efficient warning tools by local authorities, especially in remote areas. For example, the Indonesian kentongan (bamboo drum: Fig. 8.4a) is traditionally used for warning the public, notably in rural areas or during an emergency period during which electricity might be cut off, meaning that 
(a)

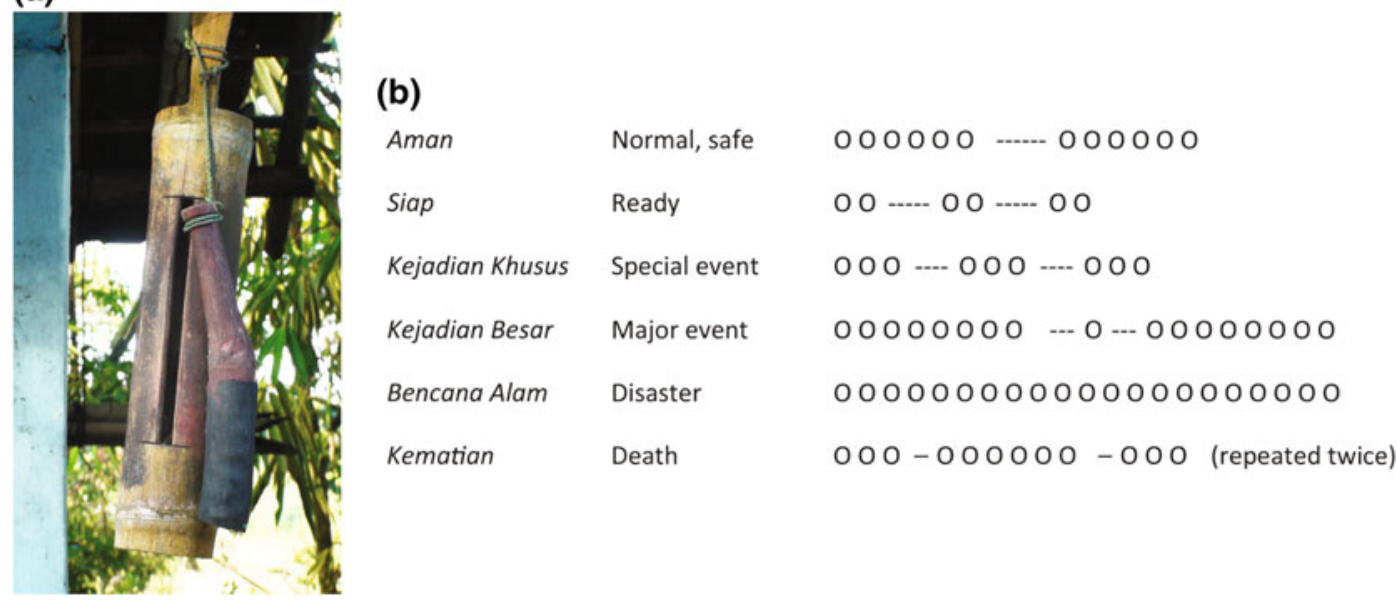

Fig. 8.4 The use of bamboo drums (kentongan) at Merapi, Indonesia. a kentongan at the entrance of a house on the West slope of Merapi (Photo F. Lavigne, 2010). b Kentongan communication codes. Source Lavigne et al. (2015)

modern alert tools relying on electricity power might be dysfunctional. Based on a field survey at Merapi in 2002, over $70 \%$ of interviewed villagers thought that the kentongan was an efficient warning system (Lavigne et al. 2008). Every kentongan code has its own meaning (Fig. 8.4b). In case of volcanic disaster, the kentongan is beaten repeatedly and continuously with the same tone. It indicates that people should immediately evacuate to a pre-determined location, which is usually a village hall. However, many people among the young generation are not able to interpret the signals anymore. Therefore, the use of this tool is forbidden during Merapi's volcanic crisis in some municipalities or villages, e.g. in Sawangan and Selo on the north slope of the volcano (Mei et al. 2013).

\subsection{Official Warning Versus Community-Based Warning}

Local communities are still using natural warning signs of various types, as exemplified on the slopes of Merapi: increase in rock fall noise, increase in fumarolic activity from the summit's crater, the descent of monkeys or other wild animals from the hills, ground shaking relating to increased seismic activity, or lightning storms caused by the emission of ash into the atmosphere. Local inhabitants can be reluctant to evacuate during a crisis if signals they are familiar with are lacking, and if they don't receive both traditional and official warning of a possible eruption (Donovan 2010). Furthermore, some culturally accepted warning signs can create a false sense of security, and it can be a struggle for some to believe those based on scientific monitoring alone. Such problems related to traditional cultural beliefs were reported not only in developing countries, but also in the USA at Mt. Kilauea in Hawaii (Gregg et al. 2004), Mount St. Helens (Greene et al. 1981), and in Italy at Mt. Etna and Mt. Vesuvius (Chester et al. 2008).

The credibility of a given warning and the validity of past warnings and evacuations, both influence the decision to evacuate. Social, economic and political forces may distort risk messages, leading to public reliance upon informal information networks (Haynes et al. 2008), e.g. social networks. Therefore, local organizations play a key role in crisis communication, as exemplified at Merapi by the actions of JalinMerapi (Jaringan Informasi Lingkar Merapi, in English Merapi Circle Information Network), a local organization supported by several NGOs working around the volcano. This 
association was established in 2006 by three community-based radio stations. During the emergency response period in 2010, JalinMerapi used various electronic media to quickly and accurately convey important information and data to support the decision making process. JalinMerapi information was transmitted through a website, social networks such as Twitter and Facebook, SMS, radio communications, telephone and through information posters in the field. JalinMerapi was managed by a voluntary network that operated $24 \mathrm{~h}$ a day during the 2010 eruption (Mei et al. 2013). Thus, repetition of warnings through different sources of the evacuation command-line increased the chances that people heeded the warning.

Community-based volcano risk communication is also exemplified by the existence of the los vigias system in Tungurahua, Ecuador. Los vigias literally means watchmen, and comprises organised surveillance of the volcano made up of local community members from different villages situated on the flanks of the volcano. The vigias system has been integrated into the official risk communication of Tungurahua managed by the Volcano Observatory of Tungurahua (Stone et al. 2014).

\section{Why Are People Reluctant to Evacuate?}

Refusal to evacuate is one of the main issues in volcanic crisis management, as exemplified during the 2010 eruption of Merapi (Fig. 8.5). Evacuations have traditionally been a difficult task to carry out because of people's reluctance to leave their homes and land. Various reasons compound people's reluctance to evacuate in case of a volcanic crisis related to PDC hazard, as exemplified at Merapi (Mei and Lavigne 2013).

First, the principal reason for hesitancy is that some people do not believe that their lives are endangered by PDCs, or that PDCs are likely in that locality. Thus differences in perception of PDC management issues by local communities and scientists or emergency planners may lead to a disruption of crisis management plans (Johnston and Ronan 2000; Ronan 2013). PDC hazard experience may create an inaccurate localized template for future eruptions, giving local people a false sense of safety (Douglas 1985; Donovan 2010). For instance, despite the efforts of officials, scientists and concerned members of the public of Montserat, about 80 people were in Zones $\mathrm{A}$ and $\mathrm{B}$ of the Exclusion Zone on 25 June 1997 (Loughlin et al. 2002). Many had become accustomed to the pyroclastic flows and had become overconfident in their own ability to judge the threat by observing repeated flows that had gradually increased runout but remained restricted to valleys. Many people had contingency plans and believed that there would be observable or audible warning signs from the volcano if the activity were to escalate significantly (Loughlin et al. 2002). The feeling of safety is enhanced with the presence of concrete structures like Sabo dams, and by increasing distance of the village from the crater. The feeling of safety felt by the local communities living further than $15 \mathrm{~km}$ from Merapi crater in 2010 was enhanced by the extent of the pyroclastic flow hazardous areas delineated by CVGHM, which did not take into account the possibility of a major explosive eruption (Mei et al. 2013). Therefore understanding how people perceive risk has become increasingly important for improving risk communication and reducing risk associated conflicts (Haynes et al. 2008).

Second, it is essential to consider the local and cultural factors in volcanic risk and crisis management (Lavigne et al. 2008). During the 2010 PDC of Merapi, the evacuation refusal of Mbah Marijan (the volcano's gatekeeper or Juru Kunci) and his followers led to the deaths of thirty-five people in Kinarhejo, a village located only $5 \mathrm{~km}$ from the summit, including the gatekeeper himself. Before this disaster, evacuation refusals along the southern flank of the volcano were mostly conditioned by trust in the gatekeeper and the feeling of being protected by his presence 


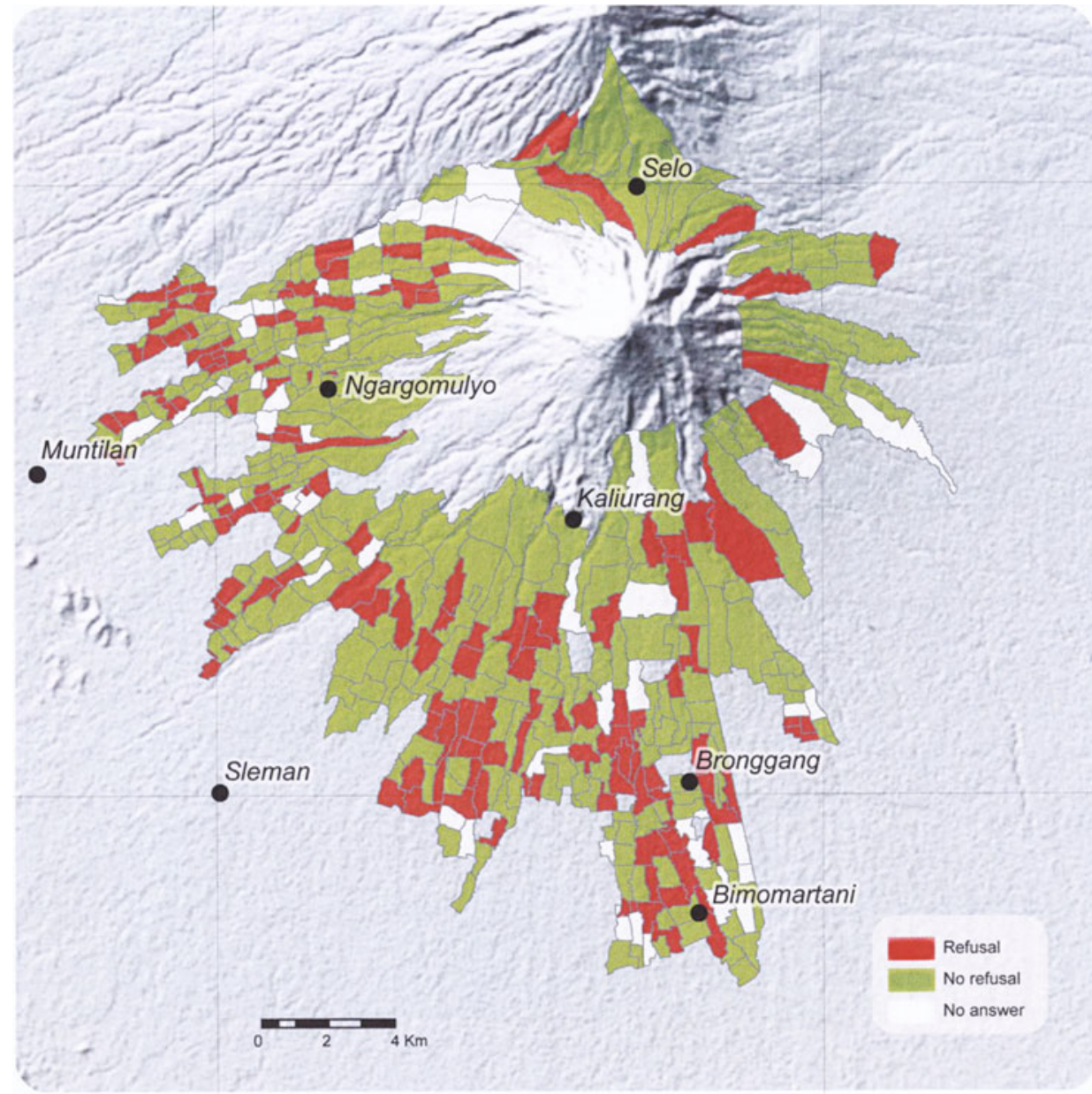

$7^{\circ} 30^{\prime} 0^{\prime \prime S}$

$7^{\circ} 40^{\prime} 0^{\prime \prime S}$

$110^{\circ} 20^{\prime} 0^{\prime \prime} E$

Fig. 8.5 Evacuation refusal during the 2010 eruption of Merapi volcano, Indonesia. Refusal means that at least one person in the village has been identified by the $110^{\circ} 30^{\prime} 0^{\prime \prime} E$

village's chief as being reluctant to evacuate after have received the warning. Source Lavigne et al. (2015)

communication within and beyond the scientific community (Donovan and Oppenheimer 2014).

Third, people may be reluctant to evacuate even if they are aware of the danger. Economic pressure may explain people's behaviour during crisis, since they often refuse to evacuate in order to cultivate their crops, take care of their animals and protect their goods. Evacuation can have severe consequences on the economy of a village or a city. During the 2007 volcanic crisis of Kelut volcano in East Java, for instance, $77 \%$ of people living in Sugihwaras, a village close to the crater did not pay attention to the warning message 
issued by the government, and almost a half of the interviewees disregarded the order to evacuate (De Belizal et al. 2012). They chose to stay at home, hiding themselves in their own houses, closing shutters and turning off lights. Almost two third of those interviewed thought it was dangerous to leave their houses and assets behind. They declared that they were afraid of potential looters, a common perception which has been deeply discussed in the literature (e.g. by Quarantelli 1984).

Some people refuse to evacuate until other family members, and also pets, are safe. A study conducted within the community living around Mayon Volcano, the Philippines, reveals how community members were not willing to stay at evacuation centers and preferred to stay with family members should an evacuation warning be issued by the authorities (Usamah and Haynes 2012). People may be reluctant to evacuate due to the sanitary situation in evacuation centres, either actual or due to rumors spread by the media. For instance, some people from Sugihwaras (Kelut) did not evacuate to the shelters during the 2008 volcanic crisis, because they heard that they were insalubrious (De Belizal et al. 2012). The media asserted that infectious diseases were spreading in many camps because of the bad quality of the food. The newspaper condemned the organizations in charge of the evacuation centres. Rumours of such diseases spread quickly and many people believed that problems occurred in every evacuation center. Such rumors have been largely covered by the literature (e.g. Drabek 1999) and may increase people's vulnerability.

\section{Building Trust in Hazard and Risk Communication to Ensure Better Responses to Evacuations}

Open and transparent communications between the stakeholders before and during a volcanic eruption is a key point in improving crisis management capabilities. In order to enhance these capabilities, it is essential to consider the local and cultural factors in volcanic risk management. As pointed out by Haynes et al. (2008), specific differences between the public, authorities and scientists are often responsible for misunderstandings and misinterpretations of information, resulting in differing perceptions of acceptable risk. Deeper understanding of the at-risk communities is therefore a key issue in order to reduce vulnerability in PDC hazard regions. Information dissemination and education of the people at risk are also key factors in correcting the perception of PDC threats, and therefore in improving crisis communication. Modes of communication should be reviewed regularly in the context of social changes. The need for community participation and involvement in raising PDC hazard awareness is crucial. Risk communication is a dialogue between the communities and people giving the warnings. The take-up of scientific advice is much more efficient when communication of that advice is founded on personal trust rather than written on a report (Haynes et al. 2007a). As a result, communication of PDC hazard directly between scientists and the public is very important, e.g. on Montserrat (Haynes 2005; Donovan and Oppenheimer 2014).

\section{Conclusion: Improving Crisis Management Capabilities for PDC's Risk Reduction}

Crisis management capabilities may be improved through a set of good practices that are theoretically well-established, but that remain difficult to develop practically by the local stakeholders.

Among the good practices for raising PDC hazard knowledge and public awareness, information related to this specific hazard should be widely disseminated, through the members of hazard mitigation offices from regional to local levels, not only within the PDC hazard zones but also involve villages and cities located tens of kilometres away from the vent. PDC hazard information should be disseminated especially 
around dormant volcanoes, where volcanic risk perception is usually low.

Video footage is an effective tool for raising PDC hazard knowledge. During the 1991 eruption of Mount Pinatubo (Philippines), the dissemination of a film from the French volcanologists M. and K. Kraft likely saved many thousands of lives. Recently, the World Organization of Volcano Observatories (WOVO) provides video resources through VOLFilm, a Multilingual and multiplatform films database for resilience to risks from volcanic hazards (http://www.wovo.org/ volfilm-multilingual-and-multi-platform-films-forresilience-to-risks-from-volcanic-hazards.html). Dissemination of information also comprises continuous media slots on PDC risk prevention, preparedness and management taking into account geographical specificities.

Community Based Disaster Risk Reduction (CBDRR) should be considered in integrating top-down and bottom-up approaches and as a channel of information and actions between stakeholders. Indeed it fosters the participation of threatened communities in both the evaluation of risk (including PDC hazards, vulnerability and capacities) and in the ways to reduce it. Community participation and involvement in raising PDC hazard awareness might be accomplished through various ways: socioeconomic factors should be better integrated from daily life to strengthen livelihoods; collaboration should be based on actual collaboration between institutional and upper level stakeholders, local stakeholders, and communities. Several approaches may be taken in order to gain more traditional knowledge of and responses to PDC-related disasters, in the framework of a bottom-up disaster risk reduction programme. Dialogue between the communities and people giving the warnings could be improved through participatory methods, e.g. participatory volcanic hazard mapping, community evacuation simulations, rural appraisal, focused group discussion or participatory three dimension mapping.

Efficient communication between scientific experts on PDC hazard, authorities, the media, local NGOs, and the population should be enhanced to improve crisis management. Information should be provided to people on time and using simple and clear language, preferably traditional language.

The need for community participation and involvement in raising PDC hazard awareness is crucial, especially among specific stakeholders, e.g. recent immigrants or daily workers coming from outside the PDC hazard zones or women, who usually have a poorer knowledge of hazards than their husband or children. Local and cultural factors should also be considered in risk and crisis management, especially because PDC hazard is often related to local myths. The 2010 Merapi disaster suggests that religion is an essential element of culture and must be carefully considered in the planning process, and not simply dismissed as a symptom of ignorance or superstition. Participatory risk management involving community leaders and their populations is most appropriate to bridge tradition, local realities and the implementation of risk management policies and strategies.

To conclude, CBDRM eventually empowers communities with self-developed and culturally acceptable ways of coping with crises due to PDC hazard.

\section{References}

Abdurachman EK, Bourdier JL, Voight B (2000) Nuées ardentes of 22 November 1994 at Merapi volcano, Java, Indonesia. J Volc Geotherm Res 100:345-361

Chester DK, Duncan AM, Dibben C (2008) The importance of religion in shaping volcanic risk perception in Italy, with special reference to Vesuvius and Etna. J Volc Geotherm Res 172:216-228

Cole PD, Calder ES, Druit TH et al (1998) Pyroclastic flows generated by gravitational instability of the 1996-97 lava dome of Soufriere Hills Volcano, Montserrat. Geoph Res Lett 25(18):3425-3428

CVGHM (Center of Volcanology and Geological Hazard Mitigation) (2002) Merapi Volcano Hazard Map. Bandung

CVGHM (Center of Volcanology and Geological Hazard Mitigation), (2011) Revised Merapi Volcano Hazard Map. Bandung 
De Belizal E, Lavigne F, Gaillard JC et al (2012) The 2007 eruption of Kelut volcano (East Java, Indonesia): phenomenology, crisis management and social response. Geomorphology 136(1):165-175

Donovan K (2010) Doing social volcanology: exploring volcanic culture in Indonesia. Area 42(1):117-126

Donovan A, Oppenheimer C (2014) Science, policy and place in volcanic disasters: insights from Montserrat. Environ Sci Policy 39:150-161

Douglas M (1985) Risk acceptability according to the social sciences. Russell Sage Foundation, New York

Drabek T (1999) Understanding disaster warning responses. Soc Sci J 36(3):515-523

Gertisser R, Charbonnier SJ, Troll VR et al (2011) Merapi (Java, Indonesia): anatomy of a killer volcano. Geol Today 27(2):57-62

Greene MR, Perry RW, Lindell MK (1981) The March 1980 eruptions of Mt. St. Helens: citizen perceptions of volcano threat. Disasters 5(1):49-66

Gregg CE, Houghton BF, Johnston DM et al (2004) The perception of volcanic risk in Kona communities from Mauna Loa and Hualalai volcanoes, Hawaii. J Volc Geotherm Res 130:179-196

Haynes K (2005) Exploring the communication of risk during a volcanic crisis: a case study of Montserrat. Unpublished Ph.D. Thesis, University of East Anglia, West Indies

Haynes K, Barclay J, Pidgeon N (2007a) The issue of trust and its influence on risk communication during a volcanic crisis. Bull Volc 70(5):605-621

Haynes K, Barclay J, Pidgeon N (2007b) Volcanic hazard communication using maps: an evaluation of their effectiveness. Bull Volcanol 70(5):123-138

Haynes K, Barclay J, Pidgeon N (2008) Whose reality counts? Factors affecting the perception of volcanic risk. J Volc Geotherm Res 172(3-4):259-272

IAVCEI Subcommittee for Crisis Protocols (1999) Professional conduct of scientists during volcanic crises. Bull Volcanol 60:323-334

Jenkins S, Komorowski JC, Baxter P et al (2013) The Merapi 2010 eruption: an interdisciplinary impact assessment methodology for studying pyroclastic density current dynamics. J Volc Geotherm Res 261:316-329

JMA (2015) Volcanic warnings. Japan Meteorological Agency. http://www.jma.go.jp/en/volcano/. Accessed 20 Jan 2015

Johnston D, Ronan K (2000) Risk education and intervention. In: Sigurdsson H, Houghton B, McNutt S et al (eds) Encyclopedia of volcanoes. Academic, San Diego, CA

Lacroix A (1904) La Montagne Pelée et ses éruptions («Mount Pelée and its eruptions» in French). Masson et Cie, Paris

Lavigne F, De Coster B, Juvin N et al (2008) People's behaviour in the face of volcanic hazards; perspectives from Javanese communities, Indonesia. J Volc Geotherm Res 172(3-4):273-287
Lavigne F, Degeai JP, Komorowski JC et al (2013) Source of the Great AD 1257 Mystery Eruption Unveiled, Samalas Volcano, Rinjani Volcanic Complex, Indonesia. Proc Nat Acad Sc USA 110 (42):16742-16747

Lavigne F, Morin J, Surono (eds) (2015) The Atlas of Merapi Volcano, 1st edn. CNRS-CVGHM, Meudon $73 \mathrm{p}$

Leonard GS, Stewart C, Wilson GS et al (2014) Integrating multidisciplinary science, modelling and impact data into evolving, syn-event volcanic hazard mapping and communication: a case study from the 2012 Tongariro eruption crisis, New Zealand. J Volc Geotherm Res 286:208-232

Leone F, Lesales T (2009) The interest of cartography for a better perception and management of volcanic risk: from scientific to social representations the case of Mt. Pelée volcano, Martinique (Lesser Antilles). J Volc Geotherm Res 186:186-194

Loughlin S, Baxter PJ, Aspinall W et al (2002) Eyewitness accounts of the 25 June 1997 pyroclastic flows and surges at Soufriere Hills Volcano, Montserrat, and implications for disaster mitigation. Geol Soc London Memoirs 21(1):211-230

Lube G, Cronin SJ, Thouret JC et al (2011) Kinematic characteristics of pyroclastic density currents at Merapi and controls on their avulsion from natural and engineered channels. Geol Soc Am Bull 123(56):1127-1140

Mei ETW, Lavigne F (2012) Influence of the institutional and socio-economic context for responding to disasters: case study of the 1994 and 2006 eruptions of the Merapi Volcano, Indonesia. Geol Soc London Spec Pub 3:171-186

Mei ETW, Lavigne F (2013) Mass evacuation of the 2010 Merapi eruption. Int J Emerg Manag 9(4):298-311

Mei ETW, Picquout A, Lavigne F et al (2013) Lessons learned from the 2010 evacuations at Merapi volcano. J Volc Geotherm Res 261:348-365

MIAVITA team (2012) Handbook for volcanic risk management-prevention, crisis management, resilience. Bureau de Recherches Géologiques et Minières (BRGM), Orléans

Nave R, Isaia R, Vilardo G et al (2010) Re-assessing volcanic hazard maps for improving volcanic risk communication: application to Stromboli Island, Italy. J Maps 6:260-269

Pardyanto L, Reksowigoro LD, Mitromartono FXS et al (1978) Volcanic hazard map, Merapi volcano, Central Java (1/100 000). Geological Survey of Indonesia, Bandung, II, p 14

Pearson L (2015) Early warning of disasters: facts and figures. http://www.scidev.net/global/communication/ feature/early-warning-of-disasters-facts-and-figures-1. html. Accessed 20 Jan 2015

Quarantelli EL (1984) People's reactions to emergency warning. Disaster Research Center, University of Delaware, Delaware 
Ronan KR (2013) Education and training for emergency preparedness. Encyclopedia of natural hazards, encyclopedia of earth sciences series: 247-249

Stone J, Barclay J, Simmons P et al (2014) Risk reduction through community-based monitoring: the vigias of Tungurahua, Ecuador. J Appl Volc 3:11
Usamah M, Haynes K (2012) An examination of the resettlement program at Mayon Volcano: what can we learn for sustainable volcanic risk reduction? Bull Volc 74(4):839-859
Open Access This chapter is distributed under the terms of the Creative Commons Attribution 4.0 International License (http://creativecommons.org/licenses/by/4.0/), which permits use, duplication, adaptation, distribution and reproduction in any medium or format, as long as you give appropriate credit to the original author(s) and the source, provide a link to the Creative Commons license and indicate if changes were made.
The images or other third party material in this chapter are included in the work's Creative Commons license, unless indicated otherwise in the credit line; if such material is not included in the work's Creative Commons license and the respective action is not permitted by statutory regulation, users will need to obtain permission from the license holder to duplicate, adapt or reproduce the material. 